\title{
SPEECH BEHAVIOUR OF ORIGINAL AND TRANSLATED TEXTS' AUTHORS: PRAGMALINGUISTIC ASPECT
}

\author{
Galina G. Matveeva \\ Don State Technical University, Rostov-on-Don, Russian Federation \\ Irina A. Zyubina \\ Southern Federal University, Rostov-on-Don, Russian Federation
}

\begin{abstract}
The authors describe speech behavior of poet Heinrich Heine and that of the author of his poetic texts' translations. The pragmalinguistic analysis of the author's speech behavior in the poem Loreley and its Russian-speaking and English-speaking translators was carried out in accordance with the implicit speech strategy "Participation / non-participation of communicants in a speech event", which is implemented in personal, social and subject aspects. The analysis shows that the speech behavior of addressers differs depending on their belonging to a particular linguaculture: the speech behavior of the German-speaking poet and the English-speaking translator as representatives of the Western mentality is similar, while it differs from the speech behavior of the Russian-speaking translators who have another type of mentality.

The pragmalinguistic analysis of the author's speech behavior in the poem Ein Fichtenbaum ('Pine') and its Russian-speaking translators was also carried out in accordance with the implicit speech strategy "The formation of a recipient's attitude to the speech event by means of evaluation". This stage of analysis reveals that the differences in the aspects of this strategy as compared to the original text testify to the translators of the poem Ein Fichtenbaum having certain personal qualities. These qualities are differently actualized in the aspect of forming positive, neutral or negative attitude to a speech event. The presented comparison however does not make it possible to draw conclusions about the translators' belonging to different linguistic cultural groups, since all the translators of this poem are Russian-speaking.

Key words: pragmalinguistics, implicit pragmalinguistics, translation, Heinrich Heine, speech portrait, speech habit, speech strategy.
\end{abstract}

Citation. Matveeva G.G., Zyubina I.A. Speech Behaviour of Original and Translated Texts' Authors: Pragmalinguistic Aspect. Vestnik Volgogradskogo gosudarstvennogo universiteta. Seriya 2, Yazykoznanie [Science Journal of Volgograd State University. Linguistics], 2017, vol. 16, no. 3, pp. 103-111. (in Russian). DOI: https:// doi.org/10.15688/jvolsu2.2017.3.10

УДК $81 ’ 25$

Дата поступления статьи: 15.03.2017

ББК 81.18 Дата принятия статьи: 12.05.2017

\section{РЕЧЕВОЕ ПОВЕДЕНИЕ АВТОРОВ ИСХОДНОГО И ПЕРЕВОДНОГО ТЕКСТОВ: ПРАГМАЛИНГВИСТИЧЕСКИЙ АСПЕКТ}

\author{
Галина Григорьевна Матвеева \\ Донской государственный технический университет, г. Ростов-на-Дону, Российская Федерация \\ Ирина Анатольевна Зюбина \\ Южный федеральный университет, г. Ростов-на-Дону, Российская Федерация
}

Аннотация. В статье на материале стихотворений Генриха Гейне описано речевое поведение автора поэтических текстов и авторов их переводов. В результате прагмалингвистического анализа речевого поведе- 
ния автора стихотворения «Лорелея» и его русскоязычных и англоязычного переводчиков в соответствии со скрытой речевой стратегией «Участие / неучастие коммуникантов в речевом событии», реализованной в личном, социальном и предметном планах, установлено, что речевое поведение адресантов различается в зависимости от их принадлежности к той или иной лингвокультуре: обнаружены общность речевого поведения немецкоговорящего поэта и англоговорящего переводчика как носителей «западной» ментальности и отличия от речевого поведения русскоговорящих переводчиков как носителей иной ментальности. В результате прагмалингвистического анализа речевого поведения автора стихотворения «Сосна» и его русскоязычных переводчиков в соответствии со скрытой речевой стратегией «Формирование у получателя отношения к речевому событию путем оценивания» установлено, что отличия показателей планов данной стратегии от оригинала свидетельствуют о наличии определенных личностных качеств у переводчиков стихотворения «Сосна». Эти качества по-разному актуализированы в плане формирования положительного, нейтрального или отрицательного отношения к речевому событию.

Ключевые слова: прагмалингвистика, скрытая прагмалингвистика, перевод, Генрих Гейне, речевой портрет, речевая привычка, речевая стратегия.

Цитирование. Матвеева Г. Г., Зюбина И. А. Речевое поведение авторов исходного и переводного текстов: прагмалингвистический аспект // Вестник Волгоградского государственного университета. Серия 2, Языкознание. - 2017. - Т. 16, № 3. - C. 103-111. - DOI: https://doi.org/10.15688/jvolsu2.2017.3.10

\section{1}

Исследование, результаты которого обобщены в статье, выполнено на материале перевода стихотворных произведений в рамках прагмалингвистического подхода к анализу речевого поведения авторов исходного и переводного текстов. С точки зрения прагмалингвистики процесс перевода характеризуется тем, что переводчик фактически выполняет две функции: получателя исходного текста и одновременно соотправителя переводного текста. Переводной текст должен свидетельствовать и об уровне понимания оригинала переводчиком, и об усилиях переводчика, направленных на достижение адекватного понимания у получателя перевода, причем эффект воздействия должен быть аналогичен тому, на который рассчитывал автор оригинала. Переводчик всегда психологически настроен на перекодирование, он должен уметь компенсировать неточности найденных лингвистических соответствий выбором других способов оформления денотата. Однако, несмотря на эту четкую цель переводческой деятельности передачу адекватного оригиналу содержания средствами другого языка, переводчик сам становится участником акта коммуникации. Как участник коммуникации он (осознанно или неосознанно) актуализирует свои личностные и социальные качества. Ср.: «Истолковывая текст, интерпретатор накладывает на него свою историческую, социально-культурную, индивидуальную парадигму <...> вне истолкования в рамках какой бы то ни было парадигмы текст вообще может быть не понят» [Богданов, 1984, с. 22]. Актуализируя свою индивидуальную парадигму, переводчик создает «фоновый шум», воспринимая который, получатель текста сможет сделать выводы о том, какой тонкий смысловой оттенок не передан или дополнительно внесен переводчиком.

Задача данной статьи - показать, как переводчик актуализирует свое речевое поведение в тексте перевода. Индивидуальное речевое поведение переводчика выявляется с помощью метода сопоставительного лингвистического анализа оригинала и его переводов. Такой сопоставительный лингвистический анализ позволяет охарактеризовать особенности речевого поведения «здесь и сейчас» автора исходного и авторов переводного текста. (Оценивание качества переводного текста по сравнению с оригиналом не входит в задачи скрытой прагмалингвистики.) В качестве материала для анализа избран поэтический текст, перевод которого усложняется по сравнению с переводом прозаического текста, поскольку необходимо соблюдение требований ритма и рифмы.

Ниже представлены результаты анализа текстов оригиналов стихотворений Генриха Гейне (Heinrich Heine) «Лорелея» («Loreley») и «Сосна» («Ein Fichtenbaum») и их различных переводов в аспекте скрытой прагмалингвистики. Исследование стихотворения «Лорелея» проведено в соответствии с 
эмотивно-ориентированной стратегией скрытого воздействия «Участие / неучастие коммуникантов в речевом событии», а стихотворения «Сосна» - в соответствии с конативноориентированной стратегией скрытого воздействия «Формирование у получателя отношения к речевому событию путем оценивания».

\section{2}

Эмотивно-ориентированная стратегия, как и эмотивная функция речи адресанта [Якобсон, 1975, с. 198], сосредоточена на отправителе текста, выражающем свое субъективно-психологическое отношение к предмету речи. Эмотивная функция связана с субъективным миром адресанта, с выражением его переживаний, его отношения к тому, что говорится; в ней находит отражение самооценка говорящего, его потребность быть услышанным, понятым [Куницына, Казаринова, Погольша, 2002, с. 61].

Стратегия «Участие / неучастие коммуникантов в речевом событии» реализуется в трех планах: личном, социальном и предметном (подробно см.: [Матвеева, 1993, c. 98-101]). При актуализации личного плана автор эксплицирует свое участие в речевом событии отправителя или получателя текста. При актуализации социального плана указывается на задействованность в коммуникации обоих участников общения - и отправителя, и получателя текста. При актуализации предметного плана адресант акцентирует внимание адресата на объективности определенного события.

Сопоставим оригинальный текст стихотворения Г. Гейне «Лорелея» с переводом на английский язык, выполненным Т. Франком, и переводами на русский язык, выполненными А. Блоком и А. Провоторовым ${ }^{1}$. Все произведения разделены на малые синтаксические группы (далее - МСГ) для дальнейшего проведения прагмалингвистического анализа. Под МСГ понимается «актуализированная предикативно-модальная группа. С точки зрения синтаксиса речь идет о реальном придаточном, простом или частях сложноподчиненного предложения» [Матвеева, 2011, с. 194]. Ниже представлены тексты для анализа, разделенные косой чертой на МСГ.
H. Heine «Loreley» (1827)

Ich weiß nicht, / was soll es bedeuten, / Daß ich so traurig bin, / Ein Märchen aus uralten Zeiten, / Das kommt mir nicht aus dem Sinn. / Die Luft ist kühl / und es dunkelt, / Und ruhig fließt der Rhein; / Der Gipfel des Berges funkelt, Im Abendsonnenschein. / Die schönste Jungfrau sitzet Dort oben wunderbar, / Ihr gold'nes Geschmeide blitzet, / Sie kämmt ihr goldenes Haar, / Sie kämmt es mit goldenem Kamme, / Und singt ein Lied dabei; / Das hat eine wundersame, / Gewalt'ge Melodei. / Den Schiffer im kleinen Schiffe, Ergreift es mit wildem Weh; / Er schaut nicht die Felsenriffe, / Er schaut nur hinauf in die Höh' / Ich glaube, / die Wellen verschlingen Am Ende Schiffer / und Kahn, / Und das hat mit ihrem Singen, / Die Loreley getan. /

(Heine H. Werke und Briefe in zehn Bänden. Bd. 1. Berlin und Weimar, 1972. S. 103-104)

«Loreley» (перевод Т. Франка, 1998)

I cannot determine the meaning Of sorrow / that fills my breast: / A fable of old, through it streaming, Allows my mind no rest. / The air is cool in the gloaming / And gently flows the Rhine. / The crest of the mountain is gleaming In fading rays of sunshine. / The loveliest maiden is sitting Up there, / so wondrously fair; / Her golden jewelry is glist'ning; / She combs her golden hair. / She combs with a gilded comb, / preening, / And sings a song, / passing time. / It has a most wondrous, appealing And pow'rful melodic rhyme. / The boatman aboard his small skiff, / Enraptured with a wild ache, / Has no eye for the jagged cliff, - / His thoughts on the heights fear forsake. / I think / that the waves will devour Both boat and man, by and by, / And that, with her dulcet-voiced power / Was done by the Loreley./

(Frank T. Die Lorelei, 1998. URL: http://ingeb.org/ Lieder/ichweiss.html)

«Лорелея» (перевод А. Блока, 1909)

Не знаю, / что значит такое, / Что скорбью я смущен; / Давно не дает покоя Мне сказка старых времен. / Прохладой сумерки веют, / И Рейна тих простор. / В вечерних лучах алеют Вершины дальних гор. / Над страшной высотою Девушка дивной красы Одеждой горит золотою, / Играет златом косы. / Златым убирает гребнем / Ипесню поет она: / В ее чудесном пенье Тревога затаена. / Пловиа на лодочке малой Дикой тоской полонит; / Забывая подводные скаль, / Он только наверх глядит. / Пловец и лодочка, / знаю, / Погибнут средь зыбей; / И всякий так погибает От песни Лорелей.

(На дальнем горизонте. Стихи и драмы зарубежных поэтов в переводе А. Блока. М. : Прогресс, 1970. С. 27-28.) 
«Лорелея» (перевод А. Провоторова, 2010)

Отчего я грушу, / я не знаю. / Как мне с этой невзгодою быть? / Сказку старых времен вспоминаю, / И не в силах ее мне забыть. / И темно, и прохладно уж стало Там, / где тихо течет старый Рейн. / И сияют громоздкие скалы В свете солнияа вечерних лучей. / И сидит на вершине та дива, / Что красивее нет на земле. / Сверху вниз она смотрит игриво, / Златьій гребень сияет в руке. / Гладит им она кудри златые / И красивую песню поет. / Пусть слова ее песни простые, / Ее голос любого проймет. / И рыбак, / эту песню усльишав, / К дивной девушке ближе подпльл. / Он смотрел в вышину, / да и рифы Из внимания он упустил. / Так и волны его поглотили Вместе с лодкой в мгновении одном.../Этот случай понять каждый в силе - / Лорелея виновнииа в том./

(Студенческий перевод)

В данных текстах выделяются следующие речевые сигналы личного плана, отражающие участие в речевом событии только отправителя или только получателя текста: эксклюзивные личные местоимения, косвенные формы эксклюзивных личных местоимений и соответствующие им притяжательные местоимения. Речевыми сигналами социального плана являются инклюзивные личные местоимения и существительные, неопределенные местоимения. Набор актуализаторов предметного плана включает в себя остаток того, что не используется для актуализации первых двух планов. Сюда относятся, например: речевые сигналы наличия действующего лица, к которому нельзя отнести участников речевого события; пассив, при котором действующее лицо или предмет выражены или выводятся из контекста, но не участвуют в речевом событии. (Полный перечень речевых маркеров стратегии «Участие / неучастие коммуникантов в речевом событии» см. в: [Зюбина, 2005, с. 71-74].)

Результаты проведенного прагмалингвистического анализа представлены в таблице 1 (за $100 \%$ принято количество МСГ в каждом переводе).

Данные таблицы свидетельствуют о совпадении речевого поведения автора исходного текста и его англоговорящего переводчика, которое выражается в полном совпадении всех трех показателей анализируемой стратегии: в текстах Г. Гейне и Т. Франка показатель предметного плана - 81,8 \%, личного плана - 18,2 \%, а показатели социального плана отсутствуют.

В переводах на русский язык наблюдается усиление личного плана стратегии «Участие / неучастие коммуникантов в речевом событии» $(22,2 \%$ у А. Блока и $21,7 \%$ у А. Провоторова по сравнению с 18,2 \% у Г. Гейне), что, по-видимому, отражает некоторую склонность русскоговорящих авторов к авторитарному типу речевого поведения. Оговоримся, что русскому коммуникативному сознанию свойственно сугубо национальное представление об ограниченном коммуникативном суверенитете личности: русское сознание считает допустимым коммуникативное вторжение в сферу практически любой личности, почти в любых условиях [Зюбина, 2005, с. 134]. В западном коммуникативном сознании доминируют коммуникативная неприкосновенность и толерантность, а в основе коммуникативного идеала находится концепт «privacy», то есть «неприкосновенность личности».

Русскоговорящие авторы при переводе не смогли избежать актуализации социального плана речевой стратегии «Участие / неучастие коммуникантов в речевом событии» (5,6 \% у А. Блока и 4,3 \% у А. Провоторова), тогда как в стихотворении Г. Гейне показатели данного плана отсутствуют. Следовательно, можно утверждать, что русскоговорящие авторы чаще актуализируют кооперативный тип речевого поведения, подсознательно на

Таблица 1

Актуализация скрытой речевой стратегии «Участие / неучастие коммуникантов в речевом событии»

\begin{tabular}{|l|c|c|c|}
\hline \multirow{2}{*}{\multicolumn{1}{|c|}{ Авторы }} & \multicolumn{3}{|c|}{ План представления стратегии } \\
\cline { 2 - 4 } & личный (\%) & социальный (\%) & предметный (\%) \\
\hline Гейне Г. (оригинал) & 18,2 & 0 & 81,8 \\
\hline Франк Т. & 18,2 & 0 & 81,8 \\
\hline Блок А. & 22,2 & 5,6 & 72,2 \\
\hline Провоторов А. & 21,7 & 4,3 & 74,0 \\
\hline
\end{tabular}


бытийном уровне учитывая менталитет и традиции соборности в России.

В ходе прагмалингвистического анализа установлено, что речевое поведение русскоговорящих и англоговорящего переводчиков отличается в зависимости от их принадлежности к той или иной лингвокультуре. Речевое поведение англоговорящего переводчика ближе немецкоговорящему поэту, поскольку и тот и другой, в отличие от русскоговорящих переводчиков, являются носителями «западной» ментальности.

\section{3}

Прежде чем обратиться к стихотворению Г. Гейне «Ein Fichtenbaum» («Сосна»), необходимо кратко изложить историю создания этого бессмертного произведения. Несмотря на большое количество филологических работ, в которых подробно анализируется названное стихотворение, каждая его строка (см., например: [Берковский, 1956; Кудрин, 2012; Лежнев, 1934; Тынянов, 1977; Хазиев, 2006; Цыбулько, 2010; Щерба, 1957; Windfuhr, 1969]), скрытая ироническая структура произведения так и осталась без внимания германистов.

Стихотворение создано в эпоху лирической гейневской полемики с молодым, завоевывающим все большую популярность германским патриотизмом, возникшим в огне наполеоновских войн: взрыв оскорбленного поражениями в тех войнах национального чувства самосознания, а затем такое же бурное его возрастание - уже после побед над французскими завоевателями. «Отцом» немецкого патриотизма был Иоганн-Готлиб Фихте (Johann Gottlieb Fichte) - великий немецкий философ, удивительным образом сопрягавший пафос метафизического одиночества человека и пафос его национально-коллективного бытия. Именно И.-Г. Фихте зимой $1807-$ 1808 гг. сочинил свои пламенные «Речи к немецкому народу» ("Reden an die deutsche Nation") [Fichte, 1997], ставшие и философской, и риторическо-публицистической основой немецкого патриотизма. Завершал он их на севере Германии, в Кенигсберге, в тени своего философского патрона Канта, умершего незадолго до приезда Фихте.
Ein Fichtenbaum steht einsam / Im Norden auf kahler Höh' "сосна (нем. Fichtenbaum) стоит одиноко на севере» - законспирированная гейневская игра с точным указанием северных реалий и выражением пафоса одиночества. В следующей строфе - Er träumt von einer Palme «ему снится пальма» - тоже гейневская игра. Что же это за «пальма»? Иоганн-Филипп Пальм (Johann Philipp Palm) не основная, но хронологически первая фигура в ряду немецких патриотов, фигура трагическая, отчасти и вдохновившая Иоганна-Готлиба Фихте.

Весной 1806 г., когда под ударами наполеоновского молота рушились германские политические миры, скромный нюрнбергский гражданин, сорокалетний издатель Пальм послал в Аугсбург патриотического содержания брошюру (по-видимому, и не им, Пальмом, написанную) «Германия в своем глубочайшем унижении» («Deutschland in seiner tiefsten Erniedrigung»). В ней обличалась германская политика Наполеона, а более всего - поведение французских войск в Баварии. Французы перехватили брошюру и показали ее Наполеону. Император пришел в ярость и распорядился вопреки всякой законности предать предполагаемого автора военному суду в двадцать четыре часа, указав и содержание приговора. Последовал немедленный расстрел, потрясший Европу и... тут же ею забытый. Суд и приведение приговора в исполнение состоялись в августе 1806 г. в южнонемецком городе Браунау - на востоке германского мира (Morgenland, как сказано у Гейне).

Таким образом, Фихте («фихтенбаум») на Севере, в своем заснеженном одиночестве; «Пальма» - Пальм далеко на знойном Востоке, одинокий и молчаливый (einsam und schweigend) тот Пальм, он и перед лицом смерти не сказал, что автор патриотической брошюры не он.

Европейское общество, очарованное удивительной музыкой гейневских стихов, не заметило скрытого в них грустно-иронического намека на двух германских патриотов.

Сопоставим оригинальный текст стихотворения Г. Гейне с переводами на русский язык, выполненными М. Лермонтовым, Ф. Тютчевым, А. Фетом, Э. Кибаловой, 
А. Провоторовым, О. Семириченко. Все произведения разделены на МСГ для дальнейшего проведения прагмалингвистического анализа.

Отметим, что перевод М. Лермонтова особенный, поскольку перед поэтом не стояло задачи изложить содержание, скопировать образы, перенести в русский текст ритм немецкого оригинала. Лермонтовский перевод - это, скорее, «перепевы» или стихотворения, созданные на мотив немецких стихотворений. Как и многие другие европейцы, Лермонтов не замечает в данном стихотворении песнь немецкому патриотизму, но в то же время он и не поддерживает мысли большинства о том, что у Гейне создан образ влюбленных, которым не суждено встретиться. Лермонтов меняет идею Гейне, он проводит свою собственную мысль.

Немецкое слово ein Fichtenbaum («сосна») мужского рода. В переводе на русский язык, сделанном, например, Ф. Тютчевым, использовано слово кедр (мужского рода), в переводе А. Фета - дуб (тоже мужского рода), а не сосна, таким образом сохранена распространенная идея об одиноких влюбленных. У М. Лермонтова и Э. Кибаловой использованы два существительных женского рода - сосна и пальма, ель и пальма соответственно, что выражает раздумья, в центре которых одиночество, поиски родной души, которая сможет тебя понять.

H. Heine «Ein Fichtenbaum» (1827)

Ein Fichtenbaum steht einsam Im Norden auf kahler Höh'. / Ihn schläfert: / mit weißer Decke Umhüllen ihn Eis / und Schnee. / Er träumt von einer Palme, / Die, fern im Morgenland, / Einsam / und schweigend trauert Auf brennender Felsenwand. I

(Heine H. Werke und Briefe in zehn Bänden. Bd. 1. Berlin und Weimar, 1972. S. 85-86) ва, 1842)

«На севере диком...» (перевод М. Лермонто-

На севере диком стоит одиноко На голой вершине сосна. / И дремлет, / качаясь, / и снегом сыпучим Одета, / как ризой, / она. / И снится ей все, / что в пустыне далекой / В том крае, / где солниа восход, / Одна / и грустна на утесе горючем Прекрасная пальма растет./

(Стихотворенія М. Лермонтова. Ч. ІІ. СПб. : Тип. Ильи Глазунова и комп., 1842. С. 123-124.)
«С чужой стороны» (перевод Ф.Тютчева, 1827)

На севере мрачном, / на дикой скале, Кедр одинокий, / подъемлясь, / белеет, / И сладко заснул он в инистой мгле, / И сон его вьюга лелеет. / Про юную пальму снится ему, / Что в краю отдаленном востока Под мирной лазурью, на светлом холму Стоит / и иветет одиноко./

(Тютчев Ф. И. Полное собрание сочинений и писем в шести томах. М. : Классика, 2002. Т. 1. Стихотворения, 1813-1849. С. 47.)

«На севере дуб одинокий» (переводА. Фета, 1841)

На севере дуб одинокий Стоит на пригорке крутом; / Он дремлет, / сурово покрытый И снежным / и ледяным ковром. / Во сне ему видится пальма В далекой восточной стране, В безмолвной, / глубокой печали, / Одна, на горячей скале.../

(Полное собрание стихотворений А. А. Фета / Приложение к журналу «Нива» на 1912 г. СПб. : Т-во А. Ф. Маркс, 1912. Т. 2. С. 214.)

«Ель стоит на лысой горке...» (перевод Э. Кибаловой, 2010)

Ель стоит на лысой горке / Тишиной окружена. / Снится ей, / что снежной горкой Вся покрыта вдруг она, / Снится на Востоке душном Пальма на скале большой, / Ей одно лишь только нужно, / Чтобы кто-нибудь пришел. /

(Студенческий перевод) 2010)

«Стоит одиноко...» (перевод А. Провоторова,

Стоит одиноко на голой вершине Огромная старая ель. / Ей снится, / что вата из тысяч снежсинок Лежит одеялом на ней. / Мечтает она о горячем Востоке, / О пальме, / что так далеко, / Которой на жгучей / горячей вершине Одной прозябать нелегко. /

(Студенческий перевод) ко, 2010)

«На севере диком...» (перевод О. Семиричен-

На севере диком, / Где снег / и холода, / Где очень одиноко / Ель выросла одна. / Она не знает солниа, / Не видела тепла, / Ей снится только вьюга, / Метелица, / пурга. / Так хочется увидеть Волшебные края, / Где солние согревает, / Где пальмы / и моря. / И все же она верит, / Что в сказочной стране, Ей все-таки удастся / Не быть наедине./

(Студенческий перевод)

Поскольку стихотворение обладает ярко выраженным лиризмом, мы обратились к конативно-ориентированной, то есть направленной на адресата, скрытой речевой стратегии 
«Формирование у получателя отношения к речевому событию путем оценивания».

Данная стратегия актуализируется в одном из трех планов: речевой план формирования автором положительного отношения получателя к речевому событию, речевой план формирования нейтрального отношения получателя к речевому событию и речевой план формирования отрицательного отношения адресата к речевому событию.

В тексте актуализация каждого из представленных планов происходит с помощью специальных маркеров. Маркерами планов формирования положительного и отрицательного отношения адресата к речевому событию мы считаем эксплицитное и имплицитное актуализирование лексических единиц, содержащих положительное или отрицательное оценивание; маркерами плана формирования нейтрального отношения к речевому событию - отсутствие выбора оценивающих лексических средств [Зюбина, 2005, с. 89], которые вызывают у получателя соответствующие позитивные, негативные или нейтральные ассоциации.

Количественный анализ актуализации планов стратегии «Формированиеу получателя отношения к речевому событию путем оценивания» у Гейне и его переводчиков представлен в таблице 2.

Как видно из таблицы, показатель формирования отрицательного отношения у Г. Гейне $-40 \%$. При актуализации плана формирования автором отрицательного отношения получателя к речевому событию, сходство обнаруживают переводы А. Провоторова $(33,3 \%)$ и О. Семириченко $(36,4 \%)$, которые наиболее близки к оригиналу. Более низ- кие показатели данного плана у Ф. Тютчева $(28,6$ \%), М. Лермонтова (25 \%) и Э. Кибаловой $(17 \%)$, что свидетельствует о желании авторов переводов вызвать менее отрицательные эмоции у адресата. Самый пессимистичный настрой в речевом поведении наблюдается у А. Фета (60 \% формирования отрицательного отношения и абсолютное отсутствие плана формирования положительного отношения).

Материал нашего исследования показывает, что план формирования автором положительного отношения получателя к речевому событию у Гейне равен нулю, что сохраняется в переводах Э. Кибаловой и А. Фета. Однако показатели выражения плана формирования автором положительного отношения получателя к речевому событию у М. Лермонтова $(14,3 \%)$, А. Провоторова (33,3\%), О. Семириченко (45,6 \%) и Ф. Тютчева (57\%) намного выше, эти переводчики стараются обращать внимание и на положительные аспекты события. Такие люди являются бо́льшими оптимистами, чем их коллеги, они более жизнерадостны, энергичны и обладают более высокой положительной установкой. Данные переводчики демонстрируют спокойствие, относительную безмятежность настроения, определенную жизнерадостность по сравнению с автором стихотворения «Сосна».

Анализ стихотворных произведений и их переводов на разные языки с использованием методики скрытой прагмалингвистики позволил выявить их зависимость от принадлежности автора и переводчиков к той или иной лин-

Таблица 2

Актуализация стратегии «Формирование у получателя отношения к речевому событию путем оценивания»

\begin{tabular}{|l|c|c|c|}
\hline \multirow{2}{*}{ Авторы } & \multicolumn{3}{|c|}{ План представления стратегии } \\
\cline { 2 - 4 } & $\begin{array}{c}\text { положительное } \\
\text { отношение (\%) }\end{array}$ & $\begin{array}{c}\text { нейтральное } \\
\text { отношение (\%) }\end{array}$ & $\begin{array}{c}\text { отрицательное } \\
\text { отношение (\%) }\end{array}$ \\
\hline Гейне Г. (оригинал) & 0 & 60 & 40,0 \\
\hline Лермонтов М. & 14,3 & 60,7 & 25,0 \\
\hline Тютчев Ф. & 57,0 & 14,4 & 28,6 \\
\hline Фет А. & 0 & 40,0 & 60,0 \\
\hline Кибалова Э. & 0 & 83,0 & 17,0 \\
\hline Провоторов А. & 33,3 & 33,4 & 33,3 \\
\hline Семириченко О. & 45,6 & 18,0 & 36,4 \\
\hline
\end{tabular}


гвокультуре и дать характеристику некоторых личностных особенностей речевого поведения автора исходного текста и его переводчиков.

\section{ПРИМЕЧАНИЕ}

${ }^{1}$ В качестве исследовательского материала в статье использованы переводы, выполненные студентами 4 курса А. Провоторовым, Э. Кибаловой, О. Семириченко, обучавшимися в Южном федеральном университете по направлению подготовки «Лингвистика».

\section{СПИСОК ЛИТЕРАТУРЫ}

Берковский, Н. Я. [Вступительная статья] / Н. Я. Берковский // Книга песен. Переводы русских поэтов / Г. Гейне. - М. : ГИХЛ, 1956. - С. 3-17.

Богданов, В. В. Деятельностный аспект семантики / В. В. Богданов // Прагматика и семантика синтаксических единиц. - Калинин : КГУ, 1984. -С. 12-23.

Зюбина, И. А. Прагмалингвистический аспект речевого поведения русскоговорящего и англоговорящего государственного обвинителя : дис. ... канд. филол. наук / Зюбина Ирина Анатольевна. Ростов-на-Дону, 2005. - 167 с.

Кудрин, О. В. Что стоит и где? О стихотворении про сосну и пальму и о его авторе Генрихе Гейне / О. В. Кудрин // Вопросы литературы. 2012. - № 4. - С. 362-401.

Куницына, В. Н. Межличностное общение / В. Н. Куницына, Н. В. Казаринова, В. М. Погольша. - СПб. : Питер, 2002. - 544 с.

Лежнев, А. 3. Два поэта. Гейне. Тютчев / А. 3. Лежнев. - М. : Худож. лит., 1934. - 351 с.

Матвеева, Г. Г. Идентификация социального лица говорящего: теория и практика / Г. Г. Матвеева. - Saarbruken : LAP LAMBERT Academic Publishing GmbH \& Co. KG, 2011. - 246 c.

Матвеева, Г. Г. Скрытые грамматические значения и идентификация социального лица («портрета») говорящего : дис. ... д-ра филол. наук / Матвеева Галина Григорьевна. - СПб., 1993. - 322 с.

Тынянов, Ю. Н. Тютчев и Гейне / Ю. Н. Тынянов // Поэтика. История литературы. Кино / Ю. Н. Тынянов. - М. : Наука, 1977. - С. 29-37.

Хазиев, В. С. Герменевтические упражнения над стихотворением Гейне "Fichtenbaum" / В. С. Хазиев // Вестник Московского университета. Сер. 7, Философия. - 2006. - № 6. - С. 42-55.

Цыбулько, О. О. Новеллистика Генриха Гейне в контексте немецкого романтизма : автореф. дис. ... канд. филол. наук / Цыбулько Олег Олегович. Москва, 2010. - 17 с.
Щерба, Л. В. Опыты лингвистического толкования стихотворений. II. «Сосна» Лермонтова в сравнении с ее немецким прототипом / Л. В. Щерба // Избранные работы по русскому языку / Л. В. Щерба. - М. : Гос. учеб.-пед. изд-во М-ва просвещения РСФСР, 1957. - С. 97-109.

Якобсон, Р. Лингвистика и поэтика / Р. Якобсон // Структурализм «за» и «против». - М. : Прогресс, 1975. - С. 193-230.

Fichte, J. G. Reden an die deutsche Nation / J. G. Fichte//Werke in zwei Bänden / J. G Fichte; Hrsg. von P. L. Oesterreich. - Frankfurt am Main : Deutscher Klassiker Verlag, 1997. - Bd. II. - S. 539-788.

Windfuhr, M. Heinrich Heine. Revolution und Reflexion / M. Windfuhr. - Stuttgart : Metzler, 1969. $300 \mathrm{~S}$.

\section{REFERENCES}

Berkovskiy N.Ya. Vstupitelnaya statya [Introductory Article]. Geyne G. Kniga pesen. Perevody russkikh poetov [Book of Songs. Translations of Russian Poets' Works]. Moscow, GIKhL Publ., 1956, pp. 3-17.

Bogdanov V.V. Deyatelnostnyy aspekt semantiki [Activity Aspect of Semantics]. Pragmatika $i$ semantika sintaksicheskikh edinits [Pragmatics and Semantics of Syntactic Units]. Kalinin, KGU Publ., 1984, pp. 12-23.

Zyubina I.A. Pragmalingvisticheskiy aspekt rechevogo povedeniya russkogovoryashchego $i$ anglogovoryashchego gosudarstvennogo obvinitelya : dis. ... kand. filol. nauk [Pragmalinguistic Aspect of Russian-Speaking and English-Speaking Public Prosecutors' Speech Behavior. Cand. philol. sci. diss.]. Rostov-on-Don, 2005. 167 p.

Kudrin O.V. Chto stoit i gde? O stihotvorenii pro sosnu i pal'mu i o ego avtore Genrihe Gejne [What stands and where? About the poem about a pine and a palm trees and its author Heinrich Heine]. Voprosy literatury, 2012, no. 4, pp. 362-401.

Kunitsyna V.N., Kazarinova N.V., Pogolsha V.M. Mezhlichnostnoe obshchenie [Interpersonal Communication]. Saint Petersburg, Piter Publ., 2002. 544 p.

Lezhnev A.Z. Dva poeta. Geyne. Tyutchev [Two Poets. Heine. Tyutchev]. Moscow, Khudozhestvennaya literatura Publ., 1934. 351 p.

Matveeva G.G. Identifikatsiya sotsialnogo litsa govoryashchego: teoriya i praktika [Identification of the Social Personality of the Speaker: Theory and Practice]. Saarbruken, LAP LAMBERT Academic Publishing GmbH \& Co. KG, 2011. 246 p.

Matveeva G.G. Skrytye grammaticheskie znacheniya i identifikatsiya sotsialnogo litsa («portreta») govoryashchego: dis. ... d-rafilol. nauk 
[Implicit Grammatical Meanings and Identification of Speaker's Social Face ("Portrait"). Dr. philol. sci. diss.]. Saint Petersburg, 1993. 322 p.

Tynyanov Yu.N. Tyutchev i Geyne [Tyutchev and Heine]. Poetika. Istoriya literatury. Kino [Poetics. History of Literature. Cinema]. Moscow, Nauka Publ., 1977, pp. 29-37.

Khaziev V.S. Germenevticheskie uprazhneniya nad stikhotvoreniem Geyne "Fichtenbaum" [Hermeneutical Exercises on Heine's Poem Fichtenbaum]. Vestnik Moskovskogo universiteta. Ser. 7, Filosofiya [Moscow University Bulletin. Philosophy], 2006, no. 6, pp. 42-55.

Tsybulko O.O. Novellistika Genrikha Geyne v kontekste nemetskogo romantizma: avtoref. dis. ... kand. filol. nauk [The Novelism of Heinrich Heine in the Context of German Romanticism. Cand. philol. sci. abs. diss.]. Moscow, 2010. 17 p.

Shcherba L.V. Opyty lingvisticheskogo tolkovaniya stikhotvoreniy. II. «Sosna» Lermontova v sravnenii s ee nemetskim prototipom [Experiments of Linguistic Interpretation of Poems. II. Lermontov's Sosna ('Pine') in Comparison with Its German Prototype]. Izbrannye raboty po russkomu yazyku [Selected Works on the Russian Language]. Moscow, Gos. ucheb.-ped. izd-vo M-va prosveshcheniya RSFSR, 1957, pp. 97-109.

Yakobson R. Lingvistika i poetika [Linguistics and Poetics]. Strukturalizm «za» $i$ «protiv» [Structuralism: "for" and "against"]. Moscow, Progress Publ., 1975, pp. 193-230.

Fichte J.G. Reden an die deutsche Nation [Talk to the German Nation]. Fichte J.G. Werke in zwei Bänden [Works in Two Volumes]. Bd. II. Hrsg. von Peter Lothar Oesterreich. Frankfurt am Main, Deutscher Klassiker Verlag, 1997, pp. 539-788.

Windfuhr M. Heinrich Heine. Revolution und Reflexion [Heinrich Heine. Revolution and Reflection]. Stuttgart, Metzler, 1969. 300 p.

\section{Information about the Authors}

Galina G. Matveeva, Doctor of Sciences (Philology), Professor, Department of World Languages and Cultures, Don State Technical University, Gagarina Sq., 1, 344000 Rostov-on-Don, Russian Federation, gegemat2337633@rambler.ru, http://orcid.org/0000-0002-6407-4274

Irina A. Zyubina, Candidate of Sciences (Philology), Associate Professor, Department of Linguistics and Professional Communication, Southern Federal University, B. Sadovaya St., 33, 344082 Rostov-on-Don, Russian Federation, iazyubina@sfedu.ru, irinazyubina@gmail.com, http://orcid.org/0000-0002-1265-8366

\section{Информация об авторах}

Галина Григорьевна Матвеева, доктор филологических наук, профессор кафедры мировых языков и культур, Донской государственный технический университет, пл. Гагарина, 1, 344000 г. Ростов-на-Дону, Российская Федерация, gegemat2337633@rambler.ru, http://orcid.org/0000-0002$6407-4274$

Ирина Анатольевна Зюбина, кандидат филологических наук, доцент кафедры лингвистики и профессиональной коммуникации, Южный федеральный университет, ул. Большая Садовая, 33, 344082 г. Ростов-на-Дону, Российская Федерация, iazyubina@sfedu.ru, irinazyubina@gmail.com, http://orcid.org/0000-0002-1265-8366 